\title{
Measurement of hardness and properties of copper alloy processed by friction stir process
}

\author{
Kazeem O, Sanusi ${ }^{1, a}$, and Esther T. Akinlabi ${ }^{1, b}$ \\ ${ }^{1}$ Department of Mechanical Engineering Science, University of Johannesburg, \\ Johannesburg 2006, South Africa.

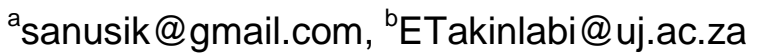

Keywords: Copper alloy, Friction stir processing, Hardness, Microstructure

\begin{abstract}
In this paper, friction stir processing (FSP) was used to refine the microstructure of the copper alloy using various parameters. The influence of the tool rotation and traverse speeds on the microstructural and mechanical properties of the processed copper alloy was measured and analyzed. Micro-hardness measurements were used to evaluate the mechanical properties of the material. The results show that copper alloy processed by FSP has an enhanced micro-hardness property than the unprocessed copper alloy, this makes the materials processed by FSP appropriate for use in industrial applications.
\end{abstract}

\section{Introduction}

Friction Stir Processing (FSP) was developed as a generic implement for microstructural modification based on the principles of FSW which can be used for changing the microstructure and the mechanical properties of conventional materials [1]. FSP technique makes use of a non-consumable rotating tool to induce heat into the material being processed $[2,3]$. The process has been used to applied to modify microstructural to improved mechanical properties through intense plastic deformation by grain refinement $[4,5]$ The advantage of FSP include densification, homogeneity of the processed material and microstructural refinement, homogenization of precipitates in various aluminium alloys and composites materials [6-8]. FSP method allow surface or bulk alloy modification by stir other elements into the alloys to become a metal matrix composite or an intermetallic alloy with wear resistance higher and hardness properties [9]. The microstructure and mechanical behaviour of light-weight materials subjected to the FSW/FSP are being studied extensively and the results shows that FSP is a suitable and effective method in producing an UFG material with good mechanical properties $[1,6,8,10]$.

In this research, study was done to investigate the way of improve the surface property, mechanical and wear resistance properties of copper alloy by using FSP technique and this will provide a better understanding of the material characteristics and wear behaviour after using FSP processing.

\section{Experimental Material and Procedures}

A copper alloy supplied as rectangular elements of dimension of $600 \times 160 \times 6 \mathrm{~mm}^{3}$ was used for this experimental research (a chemical composition is presented in Table 1). The experimental setup and H13 tool steel and hardened to $52 \mathrm{HRC}$ used as the tools is presented in Fig. 1.

The micro-hardness was measured using a micro hardness tester with a load of $300 \mathrm{~g}$ a dwell time of $15 \mathrm{~s}$. Grain sizes were recorded (see table two) after FSP.

Table 1. Chemical composition of copper alloy used.

\begin{tabular}{llllllll}
\hline $\mathrm{Cu}$ & $\mathrm{Si}$ & $\mathrm{Fe}$ & $\mathrm{Al}$ & $\mathrm{Mg}$ & $\mathrm{Zn}$ & $\mathrm{Pb}$ & $\mathrm{Ni}$ \\
\hline Balance & 0.007 & 0.009 & 0.027 & 0.05 & 0.025 & 0.017 & 0.009 \\
\hline
\end{tabular}




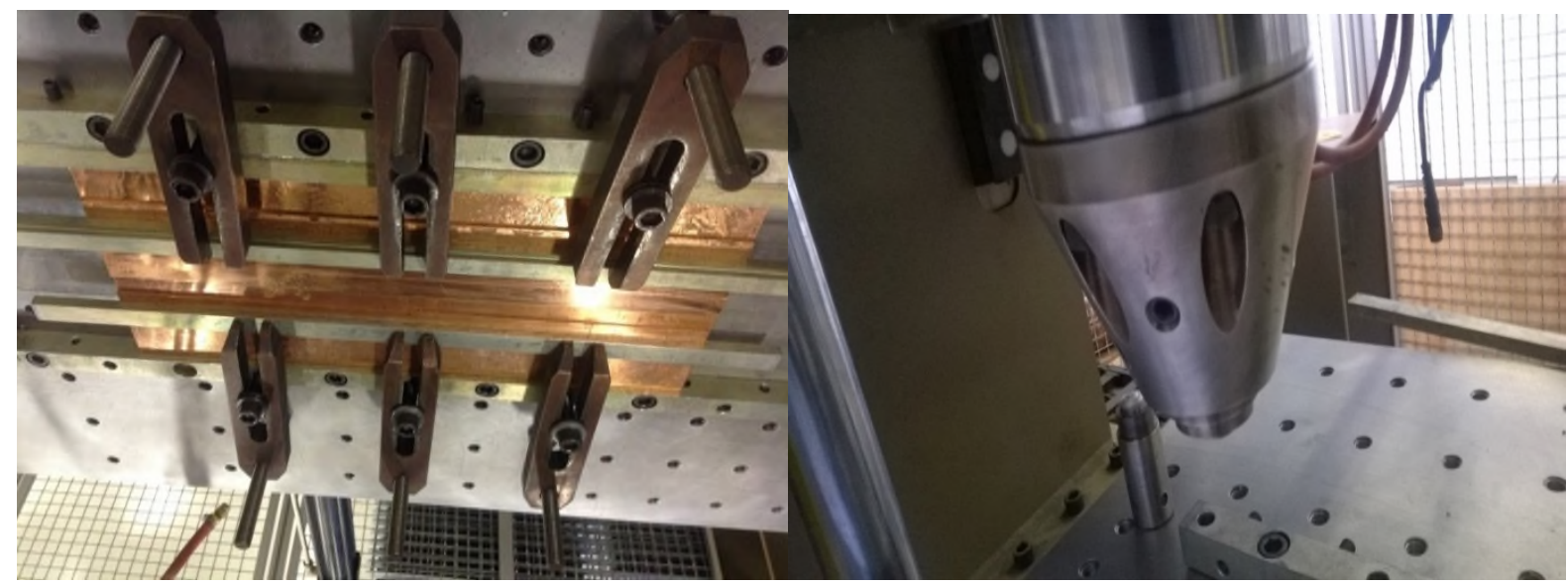

Fig. 1 The experimental setup showing the clamping fixture and the backing plate system and pinless tool used for the experiments.

\section{Experimental Results and Discussions}

Microstructure. Figs. 2-7 shows the optical electron Microstructures of the FSP process. Fig. 2 shows the microstructures of as received copper and Fig. 3 shows the microstructures of the FSP process at a rotational speed of $500 \mathrm{rpm}$ and feed rate of $100 \mathrm{~mm} / \mathrm{min}$ for one pass. The average grain size of as received and the FSP process at a rotational speed of $500 \mathrm{rpm}$ and feed rate of 100 $\mathrm{mm} / \mathrm{min}$ for one pass are 12 and $9.26 \mu \mathrm{m}$ respectively. Fig. 4 shows the microstructures of the FSP process at a rotational speed of $500 \mathrm{rpm}$ and feed rate of $100 \mathrm{~mm} / \mathrm{min}$ for three pass and Fig. 5 shows the microstructures of the FSP process at a rotational speed of $500 \mathrm{rpm}$ and feed rate of $200 \mathrm{~mm} / \mathrm{min}$ for one pass. The average grain size of the FSP process at a rotational speed of $500 \mathrm{rpm}$ and feed rate of $100 \mathrm{~mm} / \mathrm{min}$ for three pass and the FSP process at a rotational speed of $500 \mathrm{rpm}$ and feed rate of $200 \mathrm{~mm} / \mathrm{min}$ for one pass are 7.12 and $6.81 \mu \mathrm{m}$ respectively. Fig. 6 shows the microstructures of the FSP process at a rotational speed of $1000 \mathrm{rpm}$ and feed rate of $100 \mathrm{~mm} / \mathrm{min}$ for one pass and Fig. 7 shows the microstructures of the FSP process at a rotational speed of 1000 $\mathrm{rpm}$ and feed rate of $200 \mathrm{~mm} / \mathrm{min}$ for one pass and the average grain size are 9.65 and $9.44 \mu \mathrm{m}$ respectively. The average grain size is shown in Table 2. It shows that the FSP refined the grain structures of the materials. The results showed that the average grain sizes of as-received copper alloy were $12 \mu \mathrm{m}$ and between $6 \mu \mathrm{m}$ and $10 \mu \mathrm{m}$ after processing by FSP.
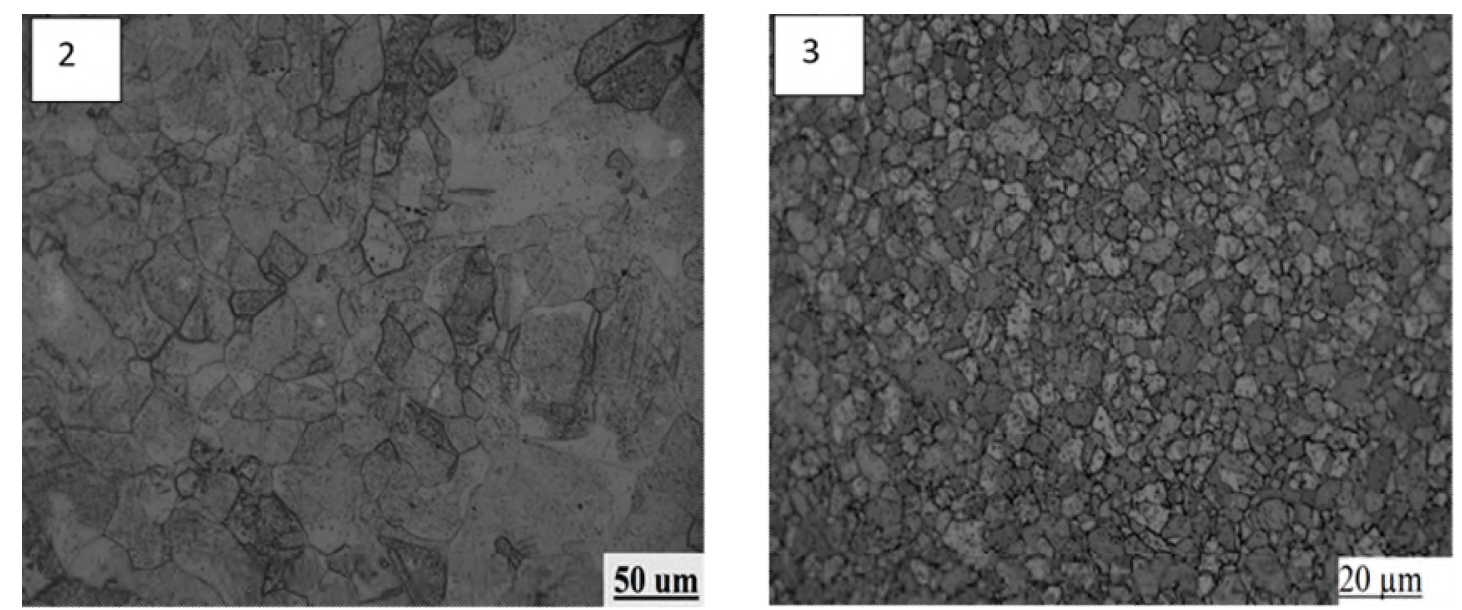

Fig. 2 Microstructures of as received material and Fig. 3 shows the Microstructures of the FSP process at a rotational speed of $500 \mathrm{rpm}$ and feed rate of $100 \mathrm{~mm} / \mathrm{min}$ for one pass. 

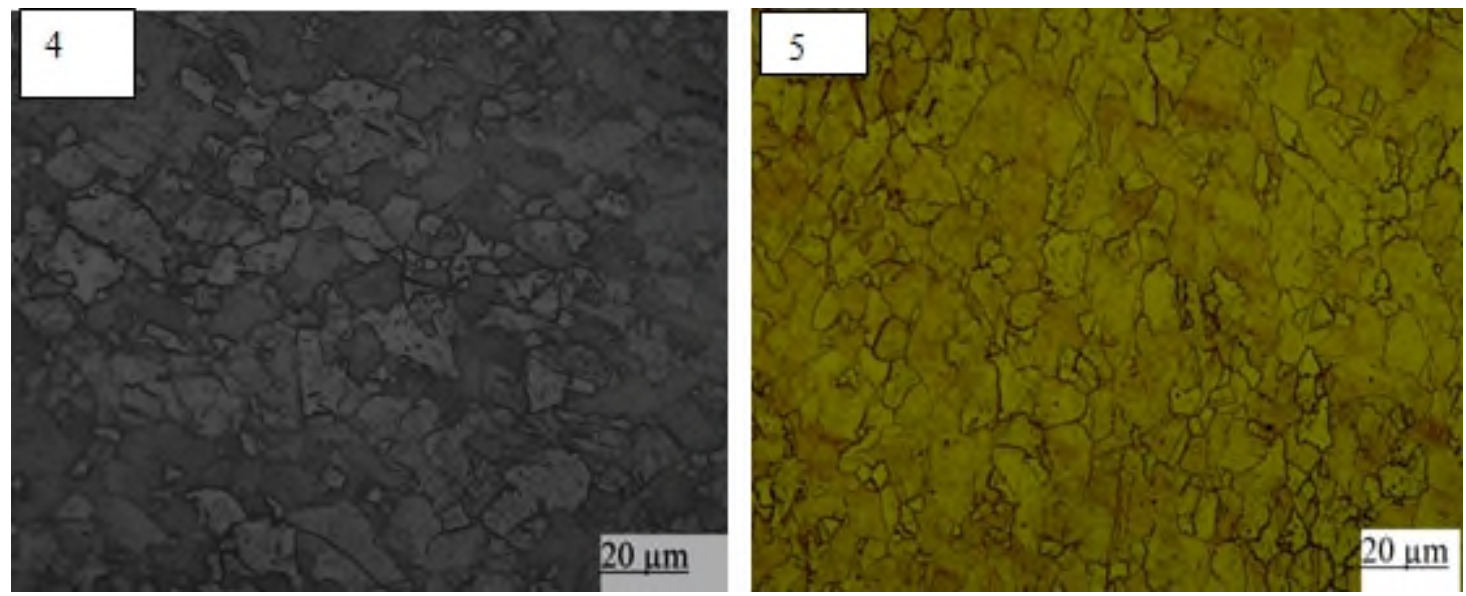

Fig. 4 Microstructures of the FSP process at a rotational speed of $500 \mathrm{rpm}$ and feed rate of $100 \mathrm{~mm} / \mathrm{min}$ for three pass and Fig. 5 Microstructures of the FSP process at a rotational speed of $500 \mathrm{rpm}$ and feed rate of $200 \mathrm{~mm} / \mathrm{min}$ for one pass
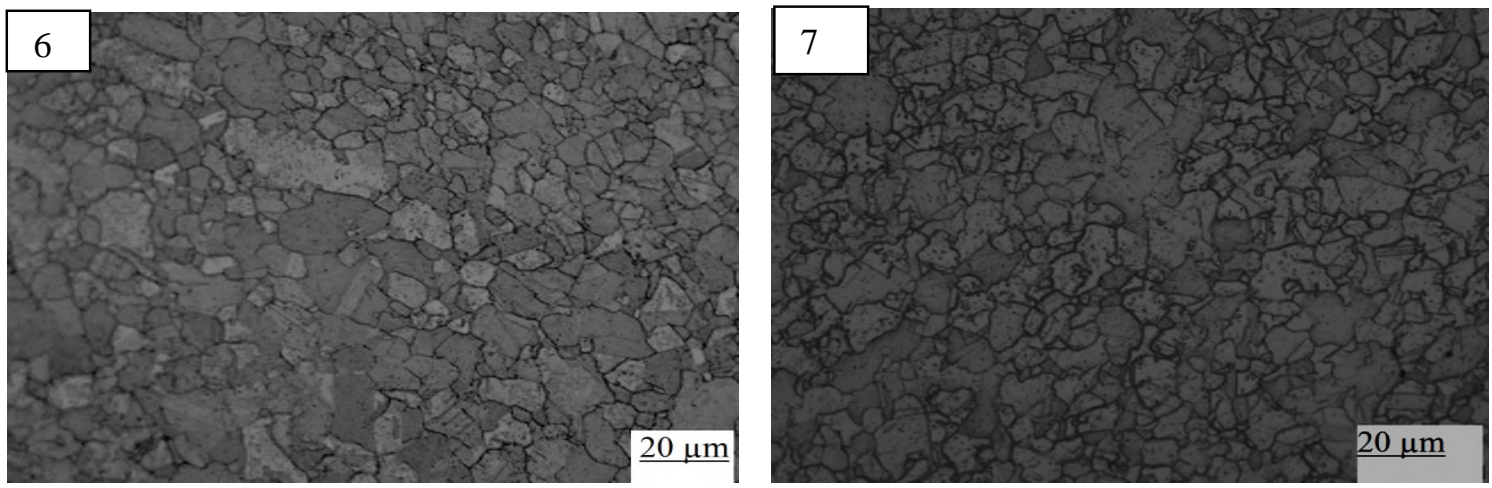

Fig. 6 shows the microstructures of the FSP process at a rotational speed of $1000 \mathrm{rpm}$ and feed rate of $100 \mathrm{~mm} / \mathrm{min}$ for one pass and Fig. 7 shows the microstructures of the FSP process at a rotational speed of $1000 \mathrm{rpm}$ and feed rate of $200 \mathrm{~mm} / \mathrm{min}$ for one pass.

Table 2. Grain sizes recorded of as received and after FSP.

\begin{tabular}{|l|l|l|}
\hline No & Parameters & Average grain size $(\mu \mathrm{m})$ \\
\hline 1 & As received copper & 12 \\
\hline 2 & $\begin{array}{l}\text { a rotational speed of } 500 \mathrm{rpm} \text { and feed rate of } 100 \mathrm{~mm} / \mathrm{min} \text { for } \\
\text { one pass }\end{array}$ & 9.26 \\
\hline 3 & $\begin{array}{l}\text { a rotational speed of } 500 \mathrm{rpm} \text { and feed rate of } 100 \mathrm{~mm} / \mathrm{min} \text { for } \\
\text { three passes }\end{array}$ & 7.12 \\
\hline 4 & $\begin{array}{l}\text { a rotational speed of } 500 \mathrm{rpm} \text { and feed rate of } 200 \mathrm{~mm} / \mathrm{min} \text { for } \\
\text { one pass }\end{array}$ & 6.81 \\
\hline 5 & $\begin{array}{l}\text { a rotational speed of } 1000 \mathrm{rpm} \text { and feed rate of } 100 \mathrm{~mm} / \mathrm{min} \text { for } \\
\text { one pass }\end{array}$ & 9.65 \\
\hline 6 & $\begin{array}{l}\text { at a rotational speed of } 1000 \mathrm{rpm} \text { and feed rate of } 200 \mathrm{~mm} / \mathrm{min} \\
\text { for one pass }\end{array}$ & 9.44 \\
\hline
\end{tabular}

\section{Micro Hardness Results}

Figs. 8-13 shows the Vickers micro-hardness measurements taken at incremental spacing of 1 $\mathrm{mm}$ were plotted as color-coded contour maps showing the distributions of the individual hardness values for each testing condition. The variation of micro hardness was taken across the disk surface. Fig. 8 shows the Vickers micro-hardness of sample processed by FSP at a rotational speed of 500 $\mathrm{rpm}$ and feed rate of $100 \mathrm{~mm} / \mathrm{min}$ for three passes using color-coded contour map, the minimum, maximum and average Vickers hardness value are 54.14, 100.1, and 68.9 Hv respectively and Fig. 9 
shows the Vickers micro-hardness of sample processed by FSP at a rotational speed of $500 \mathrm{rpm}$ and feed rate of $300 \mathrm{~mm} / \mathrm{min}$ for one pass using color-coded contour map, the minimum, maximum and average Vickers hardness value are $67.93,92.53$ and $73.89 \mathrm{Hv}$ respectively when Fig. 10 shows the Vickers micro-hardness of sample processed by FSP at a rotational speed of $500 \mathrm{rpm}$ and feed rate of $200 \mathrm{~mm} / \mathrm{min}$ for one pass using color-coded contour map, the minimum, maximum and average Vickers hardness value are 65.2, 118, and $81.54 \mathrm{Hv}$ respectively and Fig. 11 shows the Vickers micro-hardness of sample processed by FSP at a rotational speed of $1000 \mathrm{rpm}$ and feed rate of 200 $\mathrm{mm} / \mathrm{min}$ for one pass using color-coded contour map., the minimum, maximum and average Vickers hardness value are 67,98.93, and 73.77 Hv respectively, Fig. 12 shows the Vickers micro-hardness of sample processed by FSP at a rotational speed of $1000 \mathrm{rpm}$ and feed rate of $300 \mathrm{~mm} / \mathrm{min}$ for three passes using color-coded contour map, the minimum, maximum and average Vickers hardness value are 58.32, 94.93 and $68.30 \mathrm{Hv}$ respectively and Fig. 13 shows the Vickers micro hardness of sample processed by FSP at a rotational speed of $500 \mathrm{rpm}$ and feed rate of $100 \mathrm{~mm} / \mathrm{min}$ for one pass using color-coded contour map, the minimum, maximum and average Vickers hardness value are $61.73,68.33$ and $74.35 \mathrm{Hv}$ respectively.
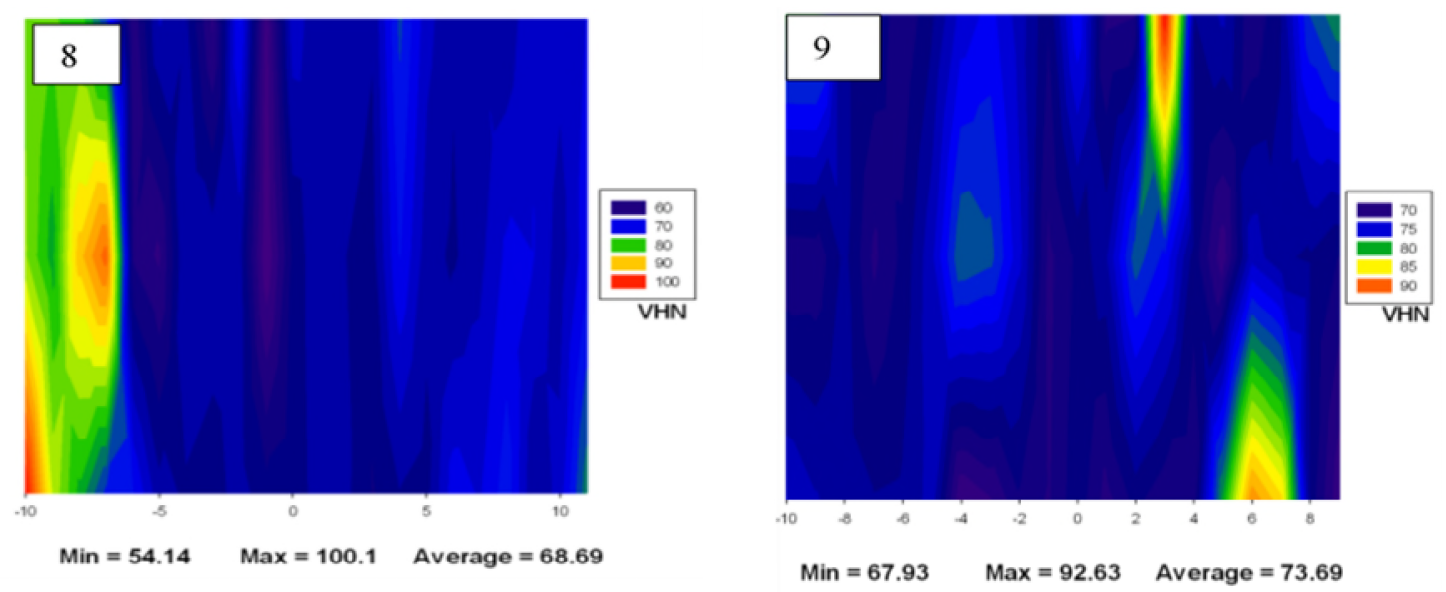

Fig. 8 shows the Vickers micro-hardness of sample processed by FSP at a rotational speed of 500 rpm and feed rate of $100 \mathrm{~mm} / \mathrm{min}$ for three passes using color-coded contour map and Fig. 9 shows the Vickers micro-hardness of sample processed by FSP at a rotational speed of $500 \mathrm{rpm}$ and feed rate of $300 \mathrm{~mm} / \mathrm{min}$ for one pass using color-coded contour map
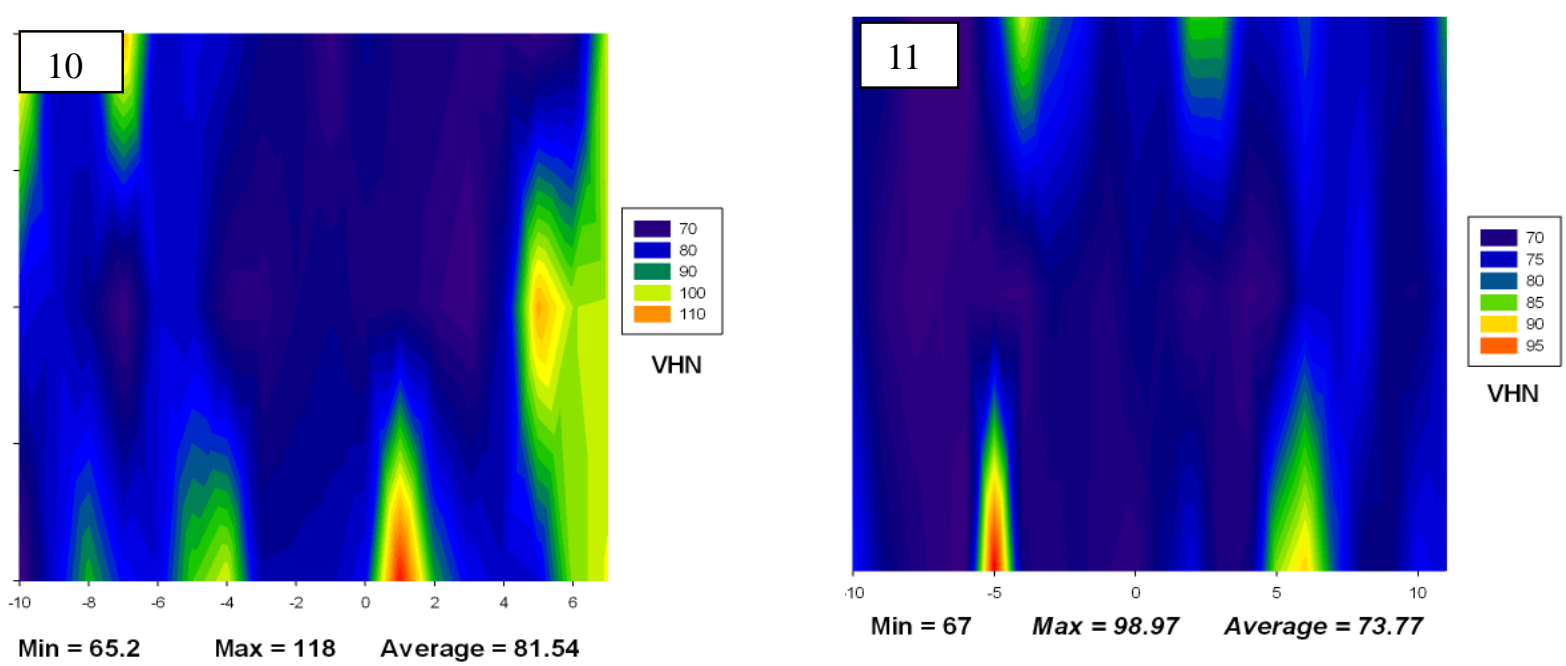

Fig. 10 shows the Vickers micro-hardness of sample processed by FSP at a rotational speed of 500 $\mathrm{rpm}$ and feed rate of $200 \mathrm{~mm} / \mathrm{min}$ for one pass using color-coded contour map and Fig .11 shows the Vickers micro-hardness of sample processed by FSP at a rotational speed of $1000 \mathrm{rpm}$ and feed rate of $200 \mathrm{~mm} / \mathrm{min}$ for one pass using color-coded contour map. 

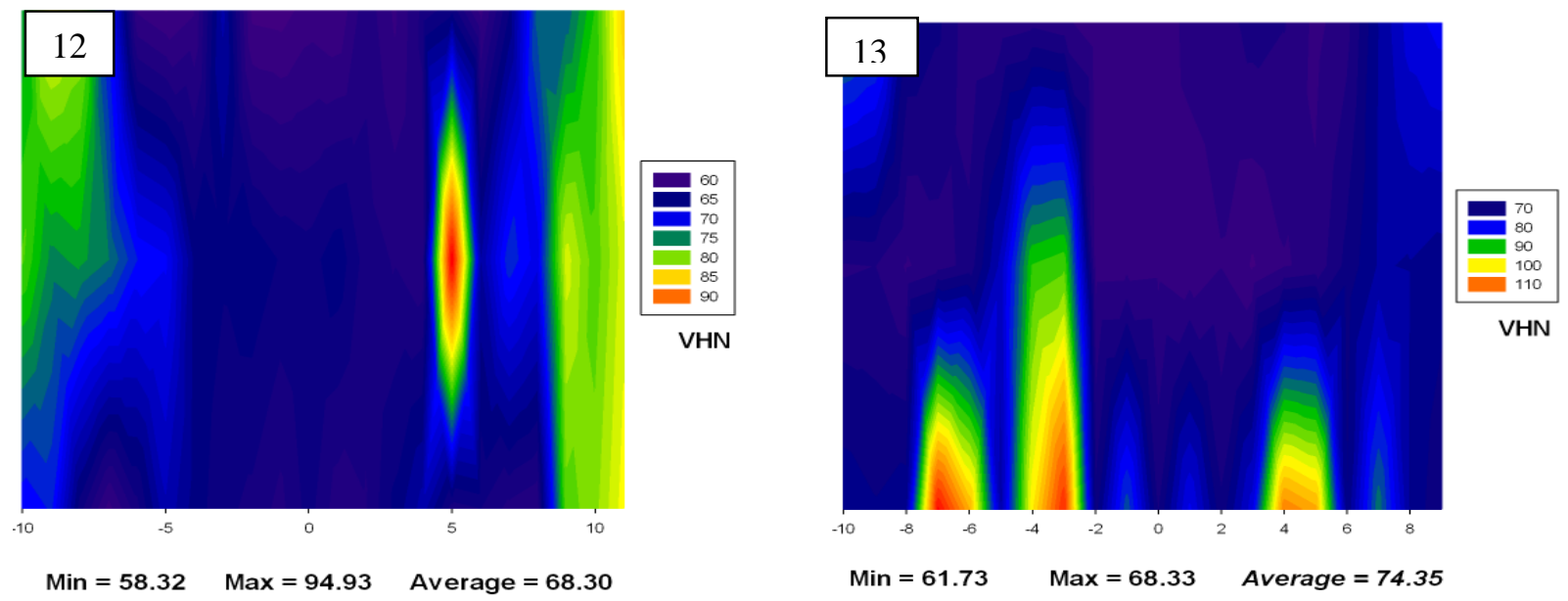

Fig. 12 shows the Vickers micro-hardness of sample processed by FSP at a rotational speed of 1000 $\mathrm{rpm}$ and feed rate of $300 \mathrm{~mm} / \mathrm{min}$ for three passes using color-coded contour map and Fig. 13 shows the Vickers micro hardness of sample processed by FSP at a rotational speed of $500 \mathrm{rpm}$ and feed rate of $100 \mathrm{~mm} / \mathrm{min}$ for one pass using color-coded contour map

\section{Conclusion}

The grain size of the copper alloy processed by FSP was refined microstructure by the intense plastic deformation. FSP process improved and enhanced microhardness property of copper alloy than unprocessed copper alloy. The higher hardness of materials processed by FSP causes a higher mass loss than in the as-received material and this appears to be inconsistent with the conventional Friction stir process is a good material process that can be use in industrial applications.

\section{Acknowledgement}

The authors gratefully acknowledge the financial supports of the National Research Foundation (NRF) South Africa, Faculty of Engineering and the Built Environment, University of Johannesburg, South Africa and the eNtsa Research Group of Nelson Mandela Metropolitan University (NMMU), Port Elizabeth, South Africa, for allowing us to use their facility.

\section{References}

[1] P. Berbon, W. Bingel, M. R. S. C. Bampton, M. Mahoney, Friction stir processing: a tool to homogenize nanocomposite aluminum alloys, Scripta Mater. 44(1) (2001) 61-66.

[2] M. M. El-Rayesa, E. A. El-Danafa, The influence of multi-pass friction stir processing on the microstructural and mechanical properties of Aluminum Alloy 6082, Mater. Proc. Tech. 212 (2012) 1157-1168.

[3] I. Galvao, A. Loureiro, D. Rodrigues, Influence of process parameters on the mechanical enhancement of copper-DHP by FSP, Adv. Mater. Res. (445) (2012) 631-636.

[4] R. Mishra, M. Mahoney, S. McFadden, N. Mara, A. Mukherjee, High strain rate superplasticity in a friction stir processed $7075 \mathrm{Al}$ alloy, Scripta Mater. 42(2) (2000) 163-168.

[5] E. Akinlabi, R. Mahamood, S. Akinlabi, E. Ogunmuyiwa, Processing Parameters Influence on Wear Resistance Behaviour of Friction Stir Processed Al-TiC Composites, Adv. Mater. Sci. Eng. 2014 (2014) 11.

[6] P. Berbon, W. Bingel, R. Mishra, C. Bampton, M. Mahoney, Friction stir processing: a tool to homogenize nanocomposite aluminum alloys, Scripta Mater. 44(1) (2001) 61-66. 
[7] Z. Ma, R. Mishra, M. Mahoney, Superplastic deformation behaviour of friction stir processed 7075Al alloy, Acta Mater. 50(17) (2002) 4419-4430.

[8] P. Cavalierea, A. Squillace, High temperature deformation of friction stir processed 7075 aluminium alloy, Mater. Charact. 55 (2005) 136-142.

[9] C. Chuang, J. Huang, P. Hsieh, Using friction stir processing to fabricate MgAlZn intermetallic alloys, Scripta Mater. 53 (2005) 1455-1460.

[10]P. Cavalierea, A. Squillace, High temperature deformation of friction stir processed 7075 aluminium alloy, Mater. Charact. 55 (2005) 136-142. 